\title{
VirtualECare: GROUP DECISION SUPPORTED BY IDEA GENERATION AND ARGUMENTATION
}

\author{
Ricardo Costa ${ }^{1}$, Paulo Novais ${ }^{2}$, João Neves ${ }^{3}$, Goreti Marreiros ${ }^{4}$, \\ Carlos Ramos ${ }^{4}$, and José Neves ${ }^{2}$
}

${ }^{1}$ College of Management and Technology - Polytechnic of Porto, Felgueiras, PORTUGAL
rcosta@estgf.ipp.pt,
${ }^{2}$ DI-CCTC, Universidade do Minho, PORTUGAL
\{pjon, jneves \}@di.uminho.pt,
${ }^{3}$ Centro Hospitalar de Vila Nova de
Gaia/Espinho-EPE,PORTUGAL
j_neves@hotmail.com
${ }^{4}$ GECAD, Institute of Engineering - Polytechnic of Porto, PORTUGAL
\{goreti, csr\}@dei.isep.ipp.pt

It is understood that Collaborative Work plays an important role in today's organizations life cycle. On the other hand, any decision that may involve a set of decision makers is, by itself, quite complex. It is under this umbrella that it will be presented the VirtualECare project, that contemplates an intelligent multi-agent system able to monitor, interact and serve its customers in need of (health)care services. We will center our attention on the system group decision and argumentation modules, which use idea generation techniques and resort to argumentation to exchange and justify belief and choice. At the end, a prototype will be presented.

\section{INTRODUCTION}

In the last years there has been a considerable increase in the number of people in need of intensive care, especially among the elderly, a phenomenon that is related to population ageing (Brown 2003). However, this is not exclusive of the elderly, as diseases as obesity, diabetes, and blood pressure have been increasing among young adults (Ford and Capewell 2007). As a new fact, it has to be dealt with by the healthcare sector, and particularly by the public one. Thus, the importance of finding new and cost effective ways for healthcare delivery are of particular importance, especially when the patients are not to be detached from their environments (WHO 2004). Following this line of thinking, a VirtualECare Multiagent System is presented in section 2, being our efforts centered on its Group Decision modules (Costa, Neves et al. 2007) (Camarinha-Matos and Afsarmanesh 2001). 
On the other hand, there has been a growing interest in combining the technological advances in the information society - computing, telecommunications and knowledge - in order to create new methodologies for problem solving, namely those that convey on Group Decision Support Systems (GDSS), based on agent perception. Indeed, the new economy, along with increased competition in today's complex business environments, takes the companies to seek complementarities, in order to increase competitiveness and reduce risks. Under these scenarios, planning takes a major role in a company life cycle. However, effective planning depends on the generation and analysis of ideas (innovative or not) and, as a result, the idea generation and management processes are crucial. Our objective is to apply the GDSS referred to above to a new area. We believe that the use of GDSS in the healthcare arena will allow professionals to achieve better results in the analysis of one's Electronically Clinical Profile (ECP). This attainment is vital, regarding the incoming to the market of new drugs and medical practices, which compete in the use of limited resources.

\section{THE VirtualECare PROJECT}

The VirtualECare project main objective is to present an intelligent multi-agent system able to monitor, interact and provide its customers with healthcare services of the utmost quality, at reasonable costs. It will be mandatory not only to interconnect different healthcare institutions, but also leisure centers, training facilities, shops and patient relatives, just to name a few. The VirtualECare Architecture is a distributed one, with their different subsystems interconnected through a network (e.g., LAN, MAN, WAN), each one with a different role (Figure 1). A top level description of the architecture machinery is given below:

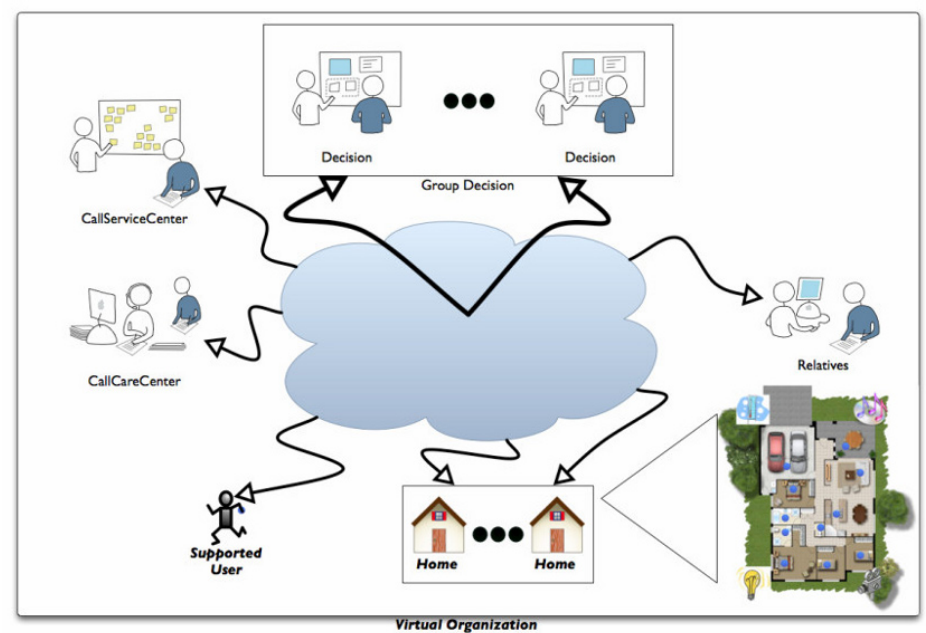

Figure 1 - The VirtualECare Architecture 
SupportedUser - elderly people with special health care needs, whose clinical data is sent to the CallCareCenter and redirected to the Group Decision Support System;

Home - the elderly natural environment, object of a continuous monitoring, where the elderly clinical data is sent to the Group Decision Support System through the CallCareCenter, being the remaining one redirected to the CallServiceCenter;

Group Decision - it is in charge of all the decisions taken at the VirtualECare platform. Our work will be centered on this key module;

CallServiceCenter - Entity with all the necessary computational and qualified personal resources, capable of receiving and analyze the diverse data and take the necessary actions according to it;

CallCareCenter - Entity in charge of computational and qualified personal resources (i.e., healthcare professionals and auxiliary), capable of receiving and analyze the clinical data, and take the necessary actions according to it;

Relatives - individuals that may have an active role in the supervising task of their love ones, being able to give precious complementary information about them and being able to intervene, in a complementary way, in specific crises (e.g., lowliness).

In order to have the Group Decision Support System at work, one has to have access not only to the belief of specialize staff (e.g., nurses, pediatrics, cardiologists), but also to the profile of the SupportedUser, leading to a better understanding of his/her special needs. The relevant information may range from the patient Electronic Clinic Record to their own personal preferences (e.g., musical, gastronomic) and/or personal experiences.

This solution will help healthcare providers to integrate, analyze and manage complex and unrelated clinical, explored and/or administrative data. It will provide tools and methodologies for creating an information-on-demand environment that can improve quality-of-living, safety, and quality of patient care.

\section{GROUP SUPPORT IN COLLABORATIVE NETWORKS ORGANIZATIONS}

\subsection{Group Support Systems}

By definition, any Collaborative Network Organization (CNO) takes for granted the existence of a group of people, aiming at the completion of a specific task (Camarinha-Matos 2003). The number of elements involved may be variable, as well as the persistency of the group. The group members may be at different places, be asynchronous on their interactions, and/or belong to different organizations. Collaborative work has not only inherent advantages (e.g., better knowledge, different world perspectives, increased acceptance), but it presents, also, some drawbacks (e.g., social pressure, domination, goal displacement, group thinking) (Marreiros, Santos et al. 2007). 


\subsection{Meeting phases}

In this work we will call meeting to all the phases necessary to the completion of a specific task, i.e., a meeting results from the interaction between two or more individuals (Bostrom, Anson et al. 2003). Physically, a meeting can be realized in one of the four scenarios: same time / same place, same time / different places, different times / same place and different times / different places. Each one of these scenarios will require from the GDSS a different kind of action.

Until now we have been talking about collaborative work and present group members as the unique people involved in the process; however, it is very common to see a third element taking part in the course of action, the facilitator. The meeting facilitator is a person welcomed in the group, nonaligned, which arbitrate all the meeting phases (Marreiros et al, 2007).

According to Dubs and Hayne (1992), a meeting has three distinct phases, as it is depicted in Figure 2.

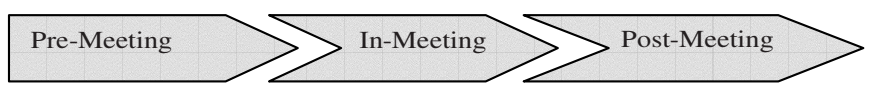

Figure 2 - Meeting Phases

In the Pre-Meeting phase the facilitator prepares the meeting, i.e., establishes the meeting goals, proceeds with the group formation (making sure that all the participants have the necessary background), selects the best tools, informs the meeting members about the goals, and distributes among them the meeting materials.

In the In-Meeting phase the participants will be working in order to accomplish the meeting goals, and the facilitator has the task of monitor the elapsing of the meeting (e.g., to observe the relationship between the group members), and to mediate if necessary.

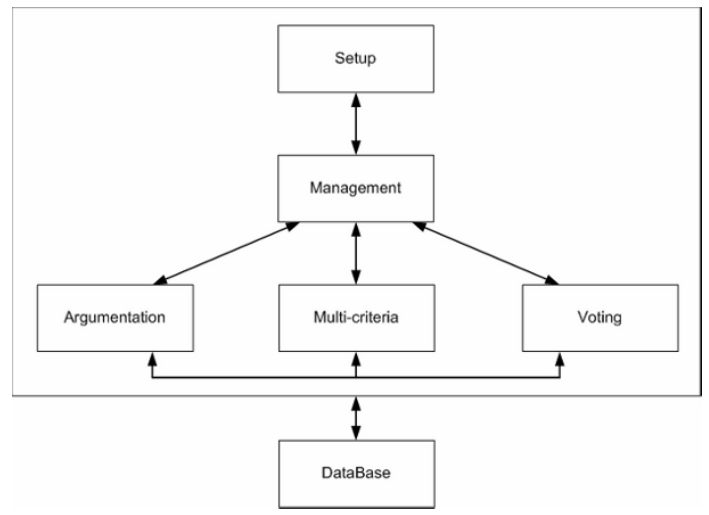

Figure 3 - VirtualECare Group Decision Architecture 
In the Post-Meeting phase it is important to evaluate the results achieved by the group, as well as how much each group member is acquit with the achieved results (satisfied/unsatisfied). Still, in this phase it is very important to identify and store information that can be helpful in future meetings (e.g., how to actualize the participant's profile for future selection). The VirtualECare Group Decision Support System Architecture is built on several modules, as it is depicted in Figure 3.

Setup module - it will be operated by a facilitator during the pre-meeting phase, in charge of configuration and parameterization activities;

Multi-criteria module - it will be operated by a facilitator during the pre-meeting phase, being in charge of the definition of the evaluation criteria and scaling of all the sub-systems;

Argumentation module - This module is based on the IBIS (Issue Based Information System) argumentation model, developed by Rittel and his colleagues in the early 70's, where an argument is a statement or a belief, which may support or pointed out to one or more thoughts (Figure 4).

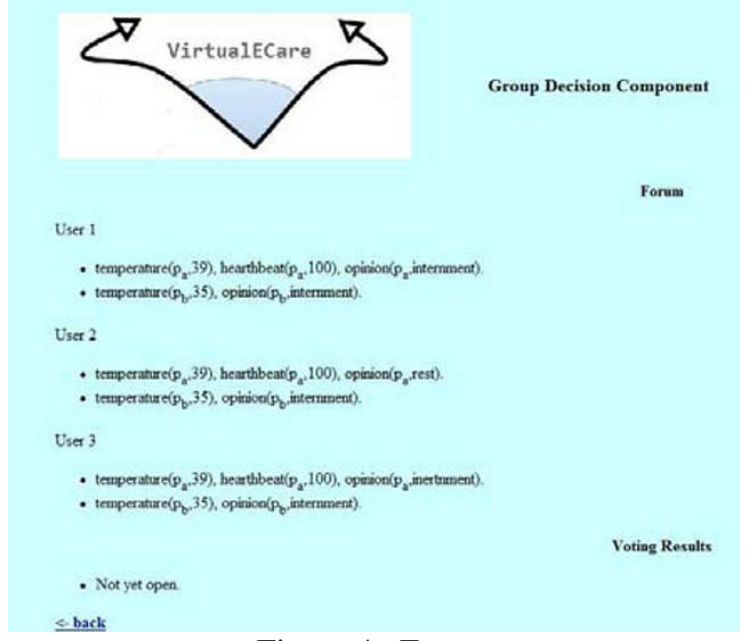

Figure 4 -Forum

Voting module - This module is responsible for allowing each intervenient of the decision group component to "vote" for his preferred choice, normally the one most similar to his "opinion" (Figure 4).

\section{IDEA GENERATION}

The Group Decision module is a major module in our system, a fact that is associated with the significance of decision-making in today business activity, and the celerity required in obtaining a solution to a problem under evaluation. Therefore, the flow of new ideas is central in an environment as the one presented above. Indeed, several idea generation techniques were popularized during the early 1950 's in order to assist organizations to be fully innovative. These techniques, although primarily born and used in the advertising world, can be applied to an 
infinite number of up-and-coming areas. Many idea techniques emerged at that time and continue nowadays, such as Brainstorming, Nominal Group Technique (NGT), Mind-mapping, SCAMPLER, among others.

In order to face the real challenges with which we have to deal with, we selected two idea generation techniques, which will be applied in two different situations:

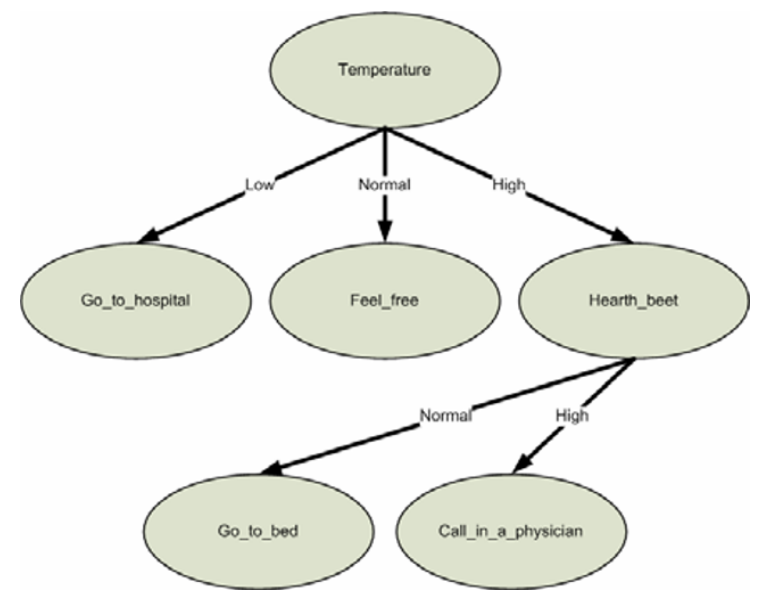

Figure 5 - A decision tree of a specific problem

- Brainstorming - it is probably the best-known creative tool. It can be used in most situations, although in most cases the rules that oversee it must be perceived by the group members. It comes with all its potential when and independent facilitator manages the process (so the group can focus on the creative tasks). In general, a brainstorming takes between 30 (thirty) minutes to 1 (one) hour, depending on the difficulty of the problem and the motivation of the decision group. Due to this detail it cannot be used in situations of life or death, but it may and is going to be used in assessing patients quality-of-life;

- Mind-mapping - it is best used when one needs to explore and/or develop ideas to help in getting a solution to a specific problem, or when we need to take notes and/or summarize meetings. It may be used to obtain instant answers in critical situations.

In Mind-mapping the specific problem is presented in the form of a decision tree, being the vital data obtained, for instance, from the sensors attached to the supported user (Figure 5).

\section{ARGUMENTATION MODULE}

Once some ideas have been put forward (e.g., through the tools referred to above, or simply by intuition) the participants are expected to "defend" those ideas, in order to reach consensus or majority. Each participant will, therefore, argue for the most interesting alternatives or against the worst ones, according to his/her preferences and/or skills. By expressing their arguments, participants expect to influence the others belief and make them change their own (Brito, Novais et al. 2003). 
This module is based on the IBIS (Issue Based Information System) argumentation model developed by Rittel and his colleagues in the early 70's (Conklin). The core of this methodology is based on a matrix of questions, ideas and arguments that, being combined, make a dialogue. According to this model, an argument is a statement or an belief which may support or pointed out one or more ideas. Among the elements of the IBIS model, there exists nine possible links, as it is depicted in Figure 6.

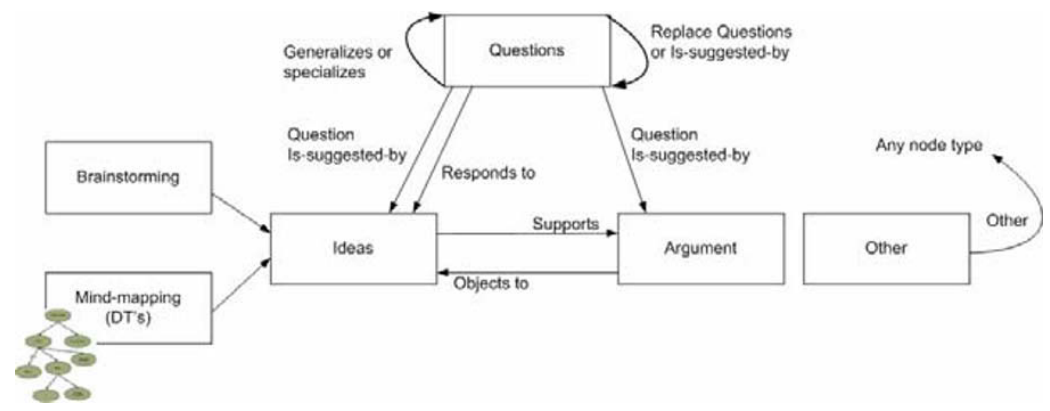

Figure 6 - IBIS model adapted from Conklin and Begeman

In the implementation process of the Group Decision apparatus, and the respective software, some modifications to the model have been made, namely:

- The question in the IBIS model maps, in the Group Decision apparatus, on the goal of the meeting;

- Ideas are the alternatives of the multi-criteria decision problem, and arise from the idea generation tool throughout brainstorming or through mind mapping;

- Arguments in IBIS can be pros or cons vis-à-vis a given idea. In the Group Decision module they are based in two types of information: Patient Electronic Clinical Profile and a set of Decision Trees. Additionally, the possibility for one participant to argue using an argument borrowed from another member, is real.

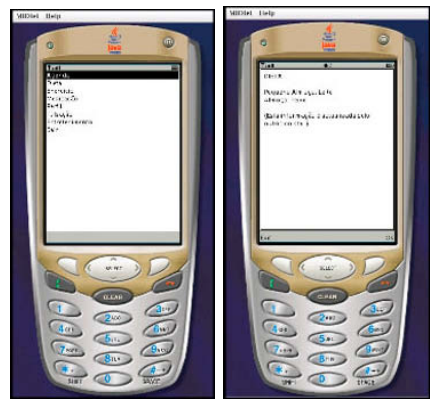

Figure 7 - A Group Decision assessment reported on a person mobile phone.

This module is paramount on the in-meeting phase. It is not only used by the participants to defend their points of view, but also in the post-meeting phase, by the 
facilitator (e.g., if the group does not reach a solution, the facilitator may use this module to check for the most consensual alternative). The IBIS model has been used over and over again in the development of GDSSs, the first realization being gIBIS (Conklin and Begeman 1988). By adopting this representation, the Group Decision module will accommodate a better organization of the arguments exchanged by the participants. This may facilitate belief convergence, and reduce the meetings "noise". Once a decision has been made, it is (automatically) sent to the person under monitorization (the supported user in Figure 1) by a mobile device (Figure 7), in order to keep him/her informed.

\section{CONCLUSION}

In the healthcare arena one aims at a distinguished deliverance of healthcare services to the population in general, and to the elderly in particular, without delocalizing or messing up with their routines. Indeed, in this paper it is described a VirtualECare multi-agent system, being studied in special its Group Decision features, aiming at multi-criteria decision problems, in order to answer to requests posted by its users (e.g., to sustain his/her ideas, each participant should argue for the most appealing or against the worst ones, according to his/her preferences and/or skills, expecting to influence the others' views).

In future work the argumentation module will be re-adjusted in order to provide not only a simple way of belief revision, but also a dialogue component to convey one beliefs, i.e., one may go from pre-argument reasoning to argument-based negotiation, influencing others through the confrontation of mental conceptions or ideas.

\section{REFERENCES}

1. Bostrom, R., R. Anson, and V. Clawson, Eds. (2003). Group facilitation and group support systems. Group Support Systems: New Perspectives, Macmillan.

2. Brito, L., P. Novais, and J. Neves (2003). The logic behind negotiation: from pre-argument reasoning to argument-based negotiaion. Intelligent Agent Software Engineering. V. Plekhanova, Idea Group Piblishing: 137-159.

3. Brown, S. J. (2003). "Next generation telecare and its roles in primary and community care." Health and social care in the community 11(6): 459-462.

4. Camarinha-Matos, L. (2003). New collaborative organizations and their research needs. PRO-VE'03, Kluwer Academic Publishers.

5. Camarinha-Matos, L. M. and H. Afsarmanesh, Eds. (2001). Virtual Communities and Elderly Support. Advances in Automation, Multimedia and Video Systems, and Modern Computer Science, WSES.

6. Conklin, J. The IBIS Manual: A short course in IBIS methodology, GDSS Inc.

7. Conklin, J. and M. Begeman (1988). gIBIS: A Hypertext tool for exploratory policy discussion.

8. Costa, R., J. Neves, P. Novais, J. Machado, L. Lima and C. Alberto, (2007). Intelligent Mixed Reality for the Creation of Ambient Assisted Living. Progress in Artificial Intelligence, Lecture Notes in Artificial Intelligence 4874, Springer, ISBN 978-3-540-77000-8.

9. S. Dubs, and S. C. Hayne (1992), "Distributed facilitation: a concept whose time has come?," in Computer Supported Cooperative Work, pp. 314-321.

10. Ford, E. S. and S. Capewell (2007). "Coronary Heart Disease Mortality Among Young Adults in the U.S. From 1980 Through 2002: Concealed Leveling of Mortality Rates." JACC(50): 2128-2132.

11. Marreiros, G., R. Santos, C. Ramos, J. Neves, P. Novais, J. Machado and J. Bulas-Cruz (2007). Ambient Intelligence in Emotion Based Ubiquitous Decision Making. Proceedings of the International Joint Conference on Artificial Intelligence (IJCAI 2007) - 2nd Workshop on Artificial Intelligence Techniques for Ambient Intelligence (AITAmI'07).

12. WHO (2004). Active ageing: towards age-friendly primary health care, World Health Organization. 